\section{Does the multi-biomarker disease activity score have diagnostic value in early rheumatoid arthritis and unclassified arthritis?}

The 2010 American College of Rheumatology (ACR) / European League Against Rheumatism (EULAR) updated classification criteria for rheumatoid arthritis (RA) focus on identifying patients at early disease stage. ${ }^{1}$ They facilitate early implementation of RA disease-modifying therapy, which has been associated with improved clinical and structural outcomes. ${ }^{2}$ Some patients with inflammatory oligoarthritis or polyarthritis initially not meeting RA classification criteria and classified with undifferentiated arthritis (UA) based on clinical and laboratory assessments, might later fulfil those criteria. ${ }^{4}$ Diagnosing these patients earlier would enable better therapeutic intervention and suppression of RA disease activity. ${ }^{5-7}$

The multi-biomarker disease activity (MBDA) score, calculated from the concentrations of 12 serum biomarkers, is an objective validated disease activity measure for patients with RA. It has been shown to track disease activity in patients with early and established RA, treatment-naïve or not, and to associate with risk of radiographic progression. ${ }^{8}$ Here we investigated whether the MBDA score might inform RA diagnosis in patients with UA.

We evaluated 126 patients from the prospective Synoviomics cohort ${ }^{9}$; 81 fulfilled ACR/EULAR 2010 criteria for RA and 45 for UA. ${ }^{14}$ At study entry, all patients had $\geq 1$ swollen joint, $<1$ year of clinical symptoms, and were naïve to diseasemodifying antirheumatic drugs and corticosteroids. Following baseline clinical assessment and serum collection, patients were treated according to EULAR guidelines. Patients were grouped as UA-UA $(n=29)$, UA-RA $(n=16)$ or RA-RA $(n=81)$ based on their fulfilment of ACR/EULAR 2010 classification criteria for $\mathrm{RA}$ at baseline and after 2 years.
Baseline MBDA score, DAS28, joint counts, acute phase protein concentrations and autoantibody status differed significantly between patient with UA and RA $(\mathrm{p}<0.005)$ (table 1$)$. Significant correlations $(\mathrm{p}<0.001)$ were observed between baseline MBDA score and DAS28 ( $\mathrm{r}=0.62)$, erythrocyte sedimentation rate (ESR) $(\mathrm{r}=0.67)$, and $\mathrm{C}$ reactive protein $(\mathrm{CRP})$ $(\mathrm{r}=0.84)$ in the overall population and separately in the RA $(\mathrm{r}=0.57 ; 0.59 ; 0.83)$ and $\mathrm{UA}(\mathrm{r}=0.63 ; 0.70 ; 0.82)$ groups.

To test whether baseline MBDA score or other disease activity measures were associated with fulfilment of RA classification criteria after 2 years, trends across the three groups (RA-RA, UA-RA and UA-UA) were evaluated using Jonckheere-Terpstra test. Statistically significant $(p<0.05)$ decreasing trends were observed for all measurements tested (figure 1). Pairwise comparisons by Wilcoxon's rank-sum test showed that baseline disease activity score based on 28 joints, ESR, CRP, swollen joint count based on 66 joints, tender joint count based on 68 joints (TJC68) and MBDA score were significantly greater in patients with RA-RA versus UA-RA $(p<0.01)$. MBDA score was not significantly different between UA-RA versus UA-UA $(p=0.132)$. Only baseline TJC68 was significantly greater in UA-RA versus UA-UA (median (IQR): 5 $(1-7.25)$ versus $1(1-3), p=0.010)$; this difference remained statistically significant after adjustment for multiple testing $(\mathrm{p}=0.019) .{ }^{10}$ Female gender was also associated with UA-RA $(14 / 16)$ versus UA-UA $(13 / 29)(\mathrm{p}=0.005)$.

In summary, baseline MBDA score did not inform fulfilment of RA classification criteria in patients with UA. However, consistent with MBDA score measuring active disease in patients with RA, baseline MBDA scores were higher in patients with an initial RA diagnosis compared with UA. Limitations to be considered include the relatively small number of patients with UA-RA and possible treatment effect on disease course in patients with UA.

\begin{tabular}{|c|c|c|c|c|}
\hline Variables & Overall $(\mathrm{N}=126)$ & $\mathrm{RA}(\mathrm{N}=81)$ & $\mathrm{UA}(\mathrm{N}=45)$ & p Value \\
\hline Female, $n(\%)$ & $88(70 \%)$ & $61(75 \%)$ & $27(60 \%)$ & 0.07 \\
\hline Age (years), median (IQR) & $51(40-58)$ & $51(39-57)$ & $51(43-59)$ & 0.457 \\
\hline Disease duration (months), median (IQR) $\dagger$ & $4(2-7.5)$ & $4(2-8)$ & $3(2-6)$ & 0.28 \\
\hline IgM-RF positive, n (\%) & $56(44 \%)$ & $49(60 \%)$ & $7(16 \%)$ & $<0.001$ \\
\hline Anti-CCP positive, $n$ (\%) & $51(40 \%)$ & $49(60 \%)$ & $2(4 \%)$ & $<0.001$ \\
\hline IgM-RF and anti-CCP positive, n (\%) & $43(34 \%)$ & $41(51 \%)$ & $2(4 \%)$ & $<0.001$ \\
\hline IgM-RF and anti-CCP negative, $\mathrm{n}(\%)$ & $62(49 \%)$ & $24(30 \%)$ & $38(84 \%)$ & $<0.001$ \\
\hline ESR (mm/h), median (IQR)† & $20(9-35)$ & $25(11-37)$ & $12(5-25)$ & 0.003 \\
\hline $\mathrm{CRP}(\mathrm{mg} / \mathrm{L})$, median $(\mathrm{IQR}) \ddagger$ & $6.2(3-22.7)$ & $8(3.7-28.3)$ & $3(1.9-12.5)$ & 0.003 \\
\hline TJC68, median (IQR) & $7.5(2-17)$ & $14(5-23)$ & $2(1-4)$ & $<0.001$ \\
\hline SJC66, median (IQR) & $5(1-9)$ & $7(4-12)$ & $2(1-3)$ & $<0.001$ \\
\hline DAS28, median (IQR)§ & $4.5(3.1-5.7)$ & $5.1(4.3-6.1)$ & $3.3(2.7-3.9)$ & $<0.001$ \\
\hline MBDA score, median (IQR) & $42(32-59)$ & $46(34-61)$ & $35(18-44)$ & 0.001 \\
\hline HAQ score, median (IQR) & $1.1(0.5-1.6)$ & $1.3(0.8-1.8)$ & $0.6(0.3-1.3)$ & 0.001 \\
\hline
\end{tabular}

\footnotetext{
*Parameters were summarised as number (n (\%)) or median (IQR) as appropriate. $\mathrm{p}$ Values were calculated using the $\chi^{2}$ test for categorical variables and Wilcoxon's rank-sum test for continuous variables.

†Values missing for 1 patient with RA and 1 patient with UA.

‡Values missing for 1 patient with RA.

§Values missing for 2 patients with RA and 1 patient with UA.

IValues missing for 4 patients with RA.

Anti-CCP, anticyclic citrullinated peptide; CRP, C reactive protein; DAS28, disease activity score based on 28 joints (based on ESR); ESR, erythrocyte sedimentation rate; HAQ, Health Assessment Questionnaire; IgM-RF, immunoglobulin M rheumatoid factor; MBDA, multi-biomarker disease activity; RA, rheumatoid arthritis; SJC66, swollen joint count based on 66 joints; TJC68, tender joint count based on 68 joints; UA, unclassified arthritis.
} 
Figure 1 Comparison of baseline disease activity measures across the diagnosis groups. Disease activity measures are shown for patients grouped according to their diagnosis at baseline and at 2 years. Thick horizontal line: median; box: IQR; whiskers: most extreme points within 1.5x IQR. $p$ Values were derived by Wilcoxon's test. $p$ values in the upper left corners represent the significance of the trends across the three groups by Jonckheere-Terpstra test. CRP, C reactive protein; DAS28, disease activity score based on 28 joints (based on ESR); ESR, erythrocyte sedimentation rate; $\mathrm{HAQ}$, Health Assessment Questionnaire; MBDA, multi-biomarker disease activity; RA, rheumatoid arthritis; SJC66, 66 swollen joint count; TJC68, 68 tender joint count; UA, unclassified arthritis.
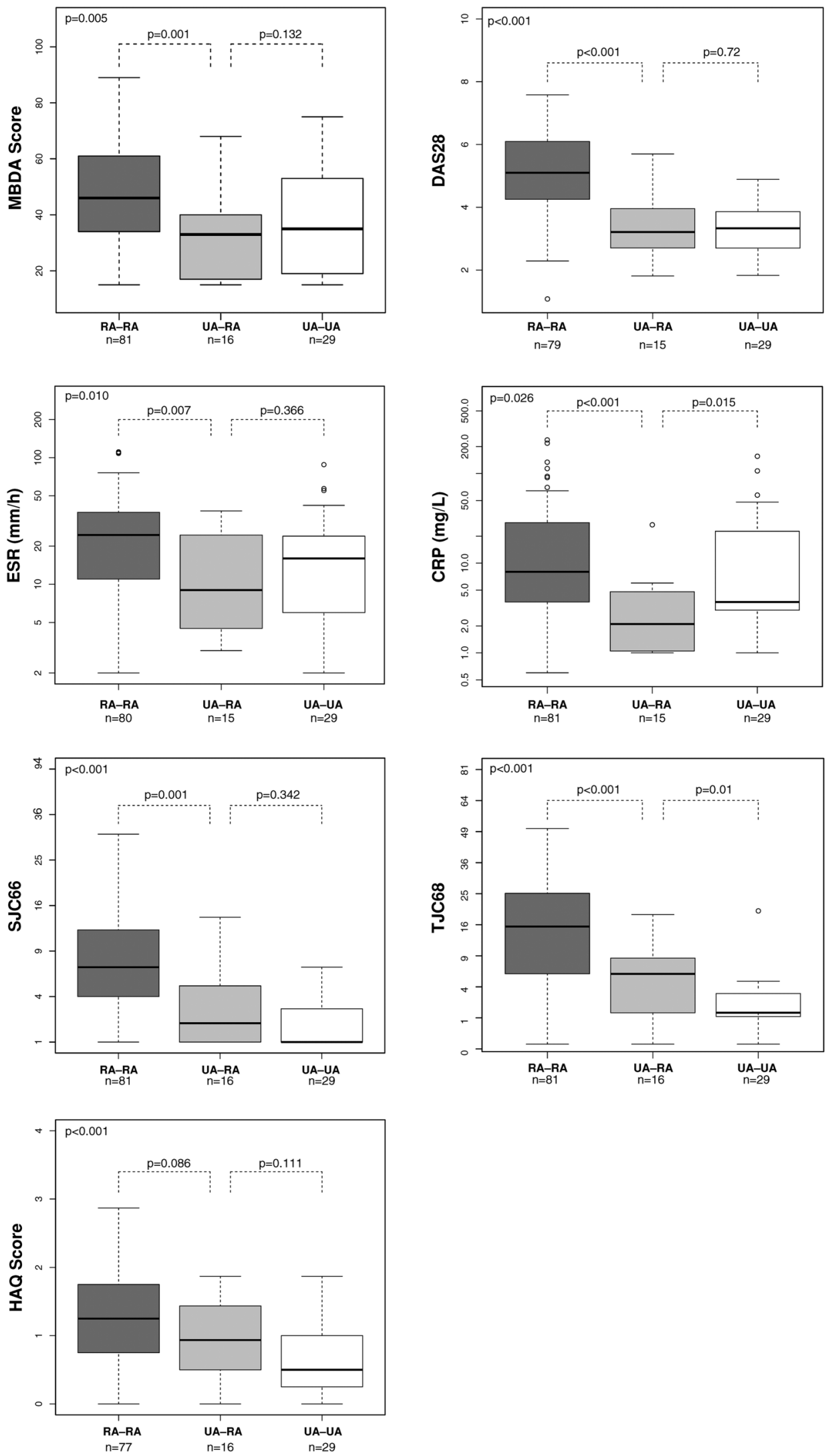
Karen I Maijer, ${ }^{1}$ Wanying $\mathrm{Li}^{2}{ }^{2}$ Eric H Sasso, ${ }^{2}$ Daniëlle M Gerlag, ${ }^{1,3}$ Nadine A Defranoux, ${ }^{2}$ Paul P Tak ${ }^{1,4,5,6}$

${ }^{1}$ Division of Clinical Immunology and Rheumatology, Academic Medical Center/ University of Amsterdam, Amsterdam, The Netherlands

${ }^{2}$ Crescendo Bioscience, Inc., South San Francisco, California, USA

${ }^{3}$ GlaxoSmithKline, Cambridge, UK

${ }^{4}$ University of Cambridge, Cambridge, UK

${ }^{5}$ Ghent University, Ghent, Belgium

${ }^{6}$ GlaxoSmithKline, Stevenage, UK

Correspondence to Dr Paul P Tak, Division of Clinical Immunology and Rheumatology, Academic Medical Center/University of Amsterdam, Meibergdreef 9 , Amsterdam 1105 AZ, The Netherlands; p.p.tak@amc.uva.nl

Acknowledgements The authors thank the study subjects for participating in this study and Arbor Communications, for editorial assistance.

Contributors KIM was involved in study design, data collection, data analysis, interpretation of data and preparing the manuscript; WL, EHS and NAD were involved in data analysis, interpretation of data and revising the manuscript critically; PPT and DMG were involved in study design, interpretation of data and revising the manuscript critically.

Funding This work was supported in part by Crescendo Bioscience, which supported shipment of the serum samples and provided biomarker analyses and statistical support. No other funding by Crescendo Bioscience was received for this study. The study was also supported by the Dutch Arthritis Foundation (grant 06-1-303 and 11-1-407), the Netherlands Organisation for Health Research and Development (ZonMw) (grant 200310003), the European Union Seventh Framework Programme (project EuroTEAM; FP7-HEALTHF2-2012-305549) and the IMI EU-funded project BeTheCure ( $\left.n^{\circ} 115142\right)$.

Competing interests PPT: also employee of GlaxoSmithKline, Stevenage, UK. DMG: also employee of GlaxoSmithKline, Cambridge, UK. GSK was not involved in this study. WL, EHS, NAD: employees of Crescendo Bioscience.

Ethics approval The study was approved by the institutional review board of the Academic Medical Center, Amsterdam, the Netherlands.

Provenance and peer review Not commissioned; externally peer reviewed.

Data sharing statement Data of our research article are available upon request.

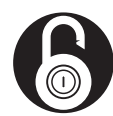

OPEN ACCESS

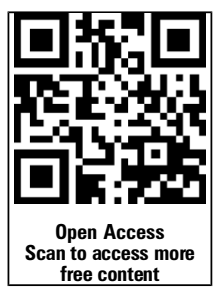

Open Access This is an Open Access article distributed in accordance with the Creative Commons Attribution Non Commercial (CC BY-NC 4.0) license, which permits others to distribute, remix, adapt, build upon this work non-commercially, and license their derivative works on different terms, provided the original work is properly cited and the use is non-commercial. See: http://creativecommons.org/ licenses/by-nc/4.0/

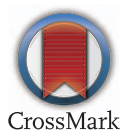

To cite Maijer KI, Li W, Sasso EH, et al. Ann Rheum Dis 2015;74:2097-2099.

Received 12 May 2015

Revised 31 July 2015

Accepted 11 August 2015

Published Online First 2 September 2015

Ann Rheum Dis 2015;74:2097-2099. doi:10.1136/annrheumdis-2015-207911
3 Finckh $\mathrm{A}$, Liang $\mathrm{MH}$, van Herckenrode $\mathrm{CM}$, et al. Long-term impact of early treatment on radiographic progression in rheumatoid arthritis: a meta-analysis. Arthritis Rheum 2006;55:864-72.

4 Gerlag DM, Raza K, van Baarsen LG, et al. EULAR recommendations for terminology and research in individuals at risk of rheumatoid arthritis: report from the Study Group for Risk Factors for Rheumatoid Arthritis. Ann Rheum Dis 2012;71:638-41.

5 Wevers-de Boer KV, Heimans L, Huizinga TW, et al. Drug therapy in undifferentiated arthritis: a systematic literature review. Ann Rheum Dis 2013;72:1436-44.

6 Verstappen SM, McCoy MJ, Roberts C, et al. Beneficial effects of a 3-week course of intramuscular glucocorticoid injections in patients with very early inflammatory polyarthritis: results of the STIVEA trial. Ann Rheum Dis 2010;69:503-9.

7 Emery P, Durez P, Dougados M, et al. The impact of T-cell co-stimulation modulation in patients with undifferentiated inflammatory arthritis or very early rheumatoid arthritis: a clinical and imaging study of abatacept: the ADJUST trial. Ann Rheum Dis 2009;69:510-16.

8 Hirata S, Defranoux N, Hanami K, et al. A multi-biomarker disease activity score for monitoring rheumatoid arthritis. Curr Biomark Find 2015 [In Press].

9 de Hair MJ, Harty LC, Gerlag DM, et al. Synovial tissue analysis for the discovery of diagnostic and prognostic biomarkers in patients with early arthritis. I Rheumatol 2011;38:2068-72.

10 Benjamini $Y$, Hochberg Y. Controlling the false discovery rate: a practical and powerful approach to multiple testing. J R Stat Soc Series B 1995;57:289-300. 